\title{
ISONIAZID THE CULPRIT BEHIND TOXIC OPTIC NEUROPATHY
}

\author{
BALAJI O, DIPANJAN B, NAVIN P*
}

Department of Pharmacology, Kasturba Medical College, Manipal, Karnataka, India. Email: Navin903@gmail.com

Received: 15 February 2017, Revised and Accepted: 13 April 2017

\begin{abstract}
Literature regarding toxic optic neuropathy (TON) due to isoniazid (INH) is scarce. This diagnosis is often missed, leading to unnecessary delay in institution of corrective measures. Often, this delay can worsen the patient's vision, with a high likelihood of development of serious damage to the patient's vision. We report a case of a 49-year-old gentleman, afflicted with meningeal tuberculosis, who developed visual disturbances following the administration of antitubercular therapy. The patient's vision improved dramatically following INH's withdrawal. This case highlighted the need to keep INH as a possible cause for TON, especially if vision does not improve following ethambutol's withdrawal. Further, this case attests to the need for thorough and periodic visual examinations in patients receiving antitubercular therapy.
\end{abstract}

Keywords: Optic neuritis, Antitubercular treatment, Reversible visual disturbance, Pyridoxine deficiency.

(C) 2017 The Authors. Published by Innovare Academic Sciences Pvt Ltd. This is an open access article under the CC BY license (http://creativecommons. org/licenses/by/4. 0/) DOI: http://dx.doi.org/10.22159/ajpcr.2017.v10i7.17797

\section{INTRODUCTION}

Tuberculosis caused by Mycobacterium tuberculosis complex is an airborn infection in $80 \%$ of cases [1]. It is a contagious infection affecting wide range of population in low income and developing countries with India being highest burden country in the world [2]. Various drug regimens are used to treat tuberculosis which includes isoniazid (INH), rifampicin, pyrazinamide, INH, and streptomycin used as first-line agents. Adverse drug reactions due to tuberculosis are very common as these drugs are given for a longer period ranging from 6 months to 2 years depending on the course of illness and diagnosis at the first place. Optic neuropathy, due to antitubercular drugs, has rarely been attributed to INH. An extensive literature search revealed only a handful of cases, where INH has been implicated as the causative agent for optic neuropathy $[3,4]$. Given that ethambutol is the more commonly associated antitubercular agent with optic neuropathy [5], the odds of overlooking INH as the offending agent is extremely high. The resultant delay in arriving on the appropriate diagnosis could manifest in serious damage to the patient's vision, maybe even optic atrophy. Further, given that the incidence of tuberculosis overall and particularly, meningeal tuberculosis is extremely high, especially in the developing nations like India [6]; it is of imminent significance that a greater awareness of the INH induced ocular disturbances be created within the scientific community. Hence, with the aim of contributing to the existing literature, we report a case of INH induced toxic optic neuropathy (TON) in a tubercular patient in a tertiary care hospital in southern India.

\section{CASE REPORT}

Informed consent was taken from the patient. A 49-year-old gentleman, devoid of any other comorbidity, was diagnosed and initiated on the first line antitubercular treatment for tubercular meningitis since October $30^{\text {th }}, 2014$. During the gentleman's follow-up visit on January $23^{\text {rd }}, 2015$, he complained of sudden, painless blurring of vision of 4 days' duration. Examination revealed features of abnormality of color vision and perimetry revealed central scotoma. As per ophthalmologist opinion optic neuritis due to ethambutol was suspected, and the drug was stopped. The gentleman was readmitted on February 21 ${ }^{\text {st }}, 2015$, with complaints of paraparesis and cord involvement, with the worsening of his visual symptoms. Fundoscopic examination revealed worsening of the inflammation of the optic nerve, and visual acuity also was markedly reduced. Hence, in light of the worsening of the ophthalmological symptomatology, a decision to withdraw INH was taken. Further, a second line anti-tubercular agent, i.e., injection amikacin $750 \mathrm{mg}$ and moxifloxacin $400 \mathrm{mg}$ once daily was started. Subsequently, during the patient's stay in the hospital over the next 10 days, there was drastic improvement in patient visual symptoms. The lack of change in the magnetic resonance imaging picture, before and post withdrawal of INH, further confirmed it to be a case of INH induced TON.

\section{DISCUSSION}

TON is one of the most underdiagnosed ophthalmologic conditions apparently diagnosed when the stage of irreversible vision loss is reached. Impairment of vision defines it due to damage caused to the optic nerve. Anterior pathway of eye is highly susceptible to damage via various toxins encountered in the workplace, eating some foods, ingesting toxins, and due to drugs without sex predilection across all populations. Reduced color vision, papillomacular bundle damage and central or cecocentral scotoma usually forms a triad in diagnosing TON. Various etiologies cause TON with both toxins and nutritional factors in tandem playing a synergistic role. It usually presents as bilateral, symmetrical painless loss of vision. Dyschromatopsia is usually the first presenting sign gradually leading to generalized loss of color perception. Loss of visual acuity usually starts as a relative scotoma slowly leading to total loss of vision with peripheral vision sparing. The one exception to this is acute loss of complete vision seen in cases of methanol poisoning. Various causes of TON are illustrated in Table 1. Pathogenesis behind TON is mainly impairment of vascular supply either to the optic nerve or to the papillomacular bundle. The optic nerve is highly susceptible to this ischemic damage due to its unusual configuration leading to accumulation of toxins; this remains unproven as of date. However, the common generalized mechanism accepted till date is mitochondrial damage and disturbance of physiological hemostasis [7].

Antitubercular medications are known to cause various side effects, and ophthalmic adverse effects have also been reported over the years. Ethambutol and INH causes optic neuropathies but TON due to ethambutol is very common when compared to INH. Ethambutol causes optic neuropathy in about $1-15 \%$ patients treated with it for tuberculosis. Proposed mechanism of ethambutol-induced TON is mainly through its zinc chelating property and its said to be due to the influx of calcium ions into the mitochondria leading to excitability [7]. It is usually dose dependent and optic neuropathy reverses itself on discontinuation of the drug. In a recent systemic review, as per literature, it was found that the incidence of ethambutol induced ocular 
Table 1: Causes of TON

\begin{tabular}{ll}
\hline Antimalarials & Chloroquine, quinine \\
Antibiotics & Sulfonamides, chloramphenicol, linezolid \\
Anticancer & Vincristine, methotrexate \\
Antitubercular & Ethambutol, INH, streptomycin \\
Heavy metals & Mercury, lead, thallium \\
Antiarrythmics & Digoxin, amiodarone \\
Others & Tobacco, carbon monoxide \\
\hline
\end{tabular}

Table 2: Adverse drug assessment

\begin{tabular}{ll}
\hline Scales & Assessment \\
\hline Naranjo's & Possible \\
Hartwig's & Moderate severity \\
Thornton's & Not preventable \\
\hline
\end{tabular}

toxicity was 22.5 per 1000 persons treated with $4.3 / 1000$ persons having permanent impairment [8].

INH-induced optic disturbances are less frequently reported. Sutton and Beattie described the first case of INH induced optic neuropathy. Jason and Bloke observed association of optic lesions in patients treated for tubercular meningitis with intrathecal INH. Incidence of INH-induced optic disturbances is not clearly known but so far 11 cases of INH-induced TON have been reported in literature. Mechanisms postulated are mainly due to disturbances in pyridoxine metabolism. It is considered that the mechanism of optic neuritis due to INH is due to loss of pyridoxine in urine and also inhibition of pyridoxal phosphate which blocks neurotransmitters. It is dose dependent, with total doses ranging from 2 to $108 \mathrm{~g}$, causing optic neuropathies. INH-induced optic neuropathy usually starts with 10 days of start of INH treatment but can occur also after a period of 2-3 months. Discontinuation of INH is highly warranted and reversibility of vision occurs quickly in 4 days but complete recovery takes 4 weeks. Very rarely it takes 6 months for reversing. Failure to stop INH results in optic atrophy [9-11].

In our case, the patient complained of vision abnormalities within 3 months of initiation of antitubercular therapy. Initially, ethambutol was suspected as the offending agent, and the drug was discontinued. Subsequently, the gentleman's vision worsened. Hence, INH was suspected as the next possible cause for the visual deterioration and discontinued. The patient improved drastically on stopping INH. Tuberculosis associated optic nerve damage was ruled out as patient did not have any other associated optic conditions such as retinitis and uveitis. It is similar to previous reports suggesting incidence of optic lesions in tubercular meningitis patients treated with INH and also total dose is $54 \mathrm{~g}$ which is well within the dose range reported to cause optic neuropathy. Other supporting factors are patient recovering immediately after discontinuation having similarity to the other case reports in literature. Hence, to establish a definite causal relationship, Naranjo's [12] causality was done and possible causality was ascribed.
Adverse reaction was moderately severe as per Hartwig's scale [13] and was not preventable as per Thornton's scale (Table 2) [14].

\section{CONCLUSION}

As TON, due to INH is a rare phenomenon, a thorough visual assessment needs to be done before and periodically subsequent to the initiation of the antitubercular therapy. The patients should be educated about the possibility of development of ophthalmological symptoms. Further, on developing visual disturbances, patients should be encouraged to report to the physician at the earliest so that corrective measures can be instituted in time. The physicians should keep in mind the possibility of INH besides ethambutol as the possible offending agent for TON. An elementary measure like withdrawal of the suspected drug can go a long way in reversing the visual symptoms. Moreover, as pyridoxine deficiency has been found to be associated with a large number of INH induced optic neuropathy cases, pyridoxine supplementation may also be carried out for such to prevent neurological complications. Further, in a bid to determine the burden of INH-induced ocular disturbances, well-designed prospective studies are the need of the hour in India.

\section{REFERENCES}

1. Shaji J, Shaikh M. Drug-resistant tuberculosis: Recent approach in polymer based nanomedicine. Int J Pharm Pharm Sci 2016;8(10):1-6.

2. Sajith M, Thomas A, Kothia JJ, Chandrakar B, Pawar A, Bargaje MD, et al. Cost of therapy incurred for tuberculosis patients receiving directly observed therapy (dot). Int J Pharm Pharm Sci 2015;7(10):141-4.

3. Kocabay G, Erelel M, Tutkun IT, Ecder T. Optic neuritis and bitemporal hemianopsia associated with isoniazid treatment in end-stage renal failure. Int J Tuberc Lung Dis 2006;10(12):1418-9.

4. González-Gay MA, Sánchez-Andrade A, Agüero JJ, Alonso MD, Rodriguez E, Criado JR. Optic neuritis following treatment with isoniazid in a hemodialyzed patient. Nephron 1993;63(3):360.

5. Rao LV, Bhandary SV, Devi AR, Ninan A, Jain V, Veluri H. Ocular toxicity of anti-tuberculous treatment. Kerala J Ophthalmol 2006;17(3):198-200.

6. Murthy JM. Tuberculous meningitis: The challenges. Neurol India 2010;58(5):716-22.

7. Sharma P, Sharma R. Toxic optic neuropathy. Indian J Ophthalmol 2011;59:137-41.

8. Koul PA. Ocular toxicity with ethambutol therapy: Timely recaution. Lung India 2015;32(1):1-3.

9. Kass I, Mandel W, Cohen H, Dressler SH. Isoniazid as a cause of optic neuritis and atrophy. J Am Med Assoc 1957;164(16):1740-3.

10. Kiyosawa M, Ishikawa S. A case of isoniazid-induced optic neuropathy. Neuroophthalmology 1981;2(1):67-70.

11. Kulkarni HS, Keskar VS, Bavdekar SB, Gabhale Y. Bilateral optic neuritis due to isoniazid (INH). Indian Pediatr 2010;47:533-5.

12. Naranjo CA, Busto U, Sellers EM, Sandor P, Ruiz I, Roberts EA, et al. A method for estimating the probability of adverse drug reactions. Clin Pharmacol Ther 1981;30(2):239-45.

13. Hartwig SC, Siegel J, Schneider PJ. Preventability and severity assessment in reporting adverse drug reactions. Am J Hosp Pharm 1992;49:2229-32.

14. Schumock GT, Thornton JP. Focusing on the preventability of adverse drug reactions. Hosp Pharm 1992;27(6):538. 